\title{
OPEN The ADP-binding kinase region of Ire1 directly contributes to its responsiveness to endoplasmic reticulum stress
}

\author{
Quynh Giang Le ${ }^{1,2}$, Yuki Ishiwata-Kimata ${ }^{1}$, Thi Huong Phuong ${ }^{1}$, Shigeto Fukunaka ${ }^{1}$, \\ Kenji Kohno ${ }^{3}$ \& Yukio Kimata ${ }^{1 凶}$
}

Upon endoplasmic-reticulum (ER) stress, the ER-located transmembrane protein, Ire1, is autophosphorylated and acts as an endoribonuclease to trigger the unfolded protein response (UPR). Previous biochemical studies have shown that Ire1 exhibits strong endoribonuclease activity when its cytosolic kinase region captures ADP. Here, we asked how this event contributes to the regulation of Ire1 activity. At the beginning of this study, we obtained a luminal-domain mutant of Saccharomyces cerevisiae Ire1, deltaldeltallIdeltaV/Y225H Ire1, which is deduced to be controlled by none of the luminal-side regulatory events. ER-stress responsiveness of deltaldeltallideltaV/Y225H Ire1 was largely compromised by a further mutation on the kinase region, D797N/K799N, which allows Ire1 to be activated without capturing ADP. Therefore, in addition to the ER-luminal domain of Ire1, which monitors ER conditions, the kinase region is directly involved in the ER-stress responsiveness of Ire1. We propose that potent ER stress harms cells' "vividness", increasing the cytosolic ADP/ATP ratio, and eventually strongly activates Ire1. This mechanism seems to contribute to the suppression of inappropriately potent UPR under weak ER-stress conditions.

The endoplasmic reticulum (ER) is a membrane-bound cellular compartment in which secretory and transmembrane proteins are folded. Furthermore, membrane lipids are biosynthesized mainly on the ER membrane. Dysfunction of the ER, which is mostly caused by, or results in, accumulation of unfolded proteins within the ER, is cumulatively referred to as ER stress and evokes the unfolded protein response (UPR) in eukaryotic cells ${ }^{1,2}$. Irel is an ER-located type-I transmembrane protein that acts as an ER-stress sensor to trigger the UPR and is conserved throughout eukaryotic species.

The cytosolic domain of Ire1 has two enzymatic activities as a Ser/Thr protein kinase and an endoribonuclease (supplementary Fig. S1). HAC1 mRNA is the sole known downstream target of Ire1 in the yeast, Saccharomyces cerevisiae. Upon ER stress, Ire1 promotes splicing of HAC1 mRNA, which is then translated into the transcription factor protein, Hac1, which is responsible for UPR gene regulation, to alleviate the stress conditions ${ }^{3-5}$. According to Kawahara et al. (1997), Hacl directly binds to the promoter element of the UPR-responsive target genes known as the UPR element (UPRE) ${ }^{6}$.

While the endoribonuclease activity directly contributes to activation of the downstream signaling pathway in the UPR, the role of the kinase region is thought to be regulatory. At least in S. cerevisiae, the sole role of Ire 1 as a kinase is trans-autophosphorylation, in which an Ire1 molecule phosphorylates another self-associated Ire1 molecule ${ }^{7}$. However, it should also be noted that the kinase region of Ire1 has another role that is not associated with phosphotransfer. The nucleotide-binding pocket of the phosphorylated Ire1 molecule captures a nucleotide that acts as a ligand for activation of Ire 1 as an endoribonuclease ${ }^{8,9}$. According to Korennykh et al. (2011), ADP works far more effectively than ATP as the activation ligand ${ }^{10}$. Nevertheless, the physiological meaning of this phenomenon remains unclear.

The luminal moiety of Ire1 controls its self-association status and is believed to serve as the ER stress-sensory domain $^{11}$. According to various experimental approaches taken by us and others ${ }^{12-14}$, the luminal domain of $S$. cerevisiae Ire1 has been shown to carry two intrinsically disordered segments, namely Subregions I and V, and

${ }^{1}$ Division of Bioscience, Graduate School of Science and Technology, Nara Institute of Science and Technology, 8916-5 Takayama, Ikoma, Nara 630-0192, Japan. ${ }^{2}$ Institute of Biotechnology, Vietnam Academy of Science and Technology, 18 Hoang Quoc Viet road, Cau Giay, Ha Noi, Vietnam. ${ }^{3}$ Graduate School of Life Science, University of Hyogo, 3-2-1 Kouto, Kamigori-cho, Ako-gun, Hyogo 678-1297, Japan. ${ }^{-}$email: kimata@bs.naist.jp 
one tightly folded segment, which is known as the core luminal domain (cLD; supplementary Fig. S1). Under non-stress conditions, the ER-located molecular chaperone, BiP, is associated with Subregion V, which is juxtamembrane positioned, to suppress the self-association of Ire $1^{12,15}$. The $\mathrm{N}$-terminally positioned segment, Subregion I, also inhibits self-association of Ire $1^{16}$. Upon ER stress, BiP dissociates from Ire1, which then self-associates probably as a dimer ${ }^{15,17-19}$. When dimerized, the cLD forms a groove that is likely to directly capture unfolded proteins accumulated in the $\mathrm{ER}^{14,20}$. This event also contributes to the full evocation of the UPR by promoting higher-order oligomerization of Ire $1^{20,21}$.

Nevertheless, as initially suggested by Liu et al. (2000), it is unlikely that the responsiveness of Ire1 to ER stress is only based on its luminal domain ${ }^{22}$. In the present study, we thus asked how Ire1 is regulated dependently by the molecular events on the cytosolic side. We produced S. cerevisiae Ire1 mutants that are likely to bypass all of the previously known regulatory events on its luminal side, and demonstrated that they are still controlled in a kinase-region-dependent manner. Our findings illustrate the physiological meaning of the kinase regiondependent regulation of Ire1.

\section{Results}

The Y $225 \mathrm{H}$ mutation leads Ire1 to be activated without physical interaction between the CLD and unfolded proteins. The $\Delta \mathrm{I} \Delta \mathrm{V}$ mutant of $S$. cerevisiae Ire1, which lacks almost all of subregions I and V, does not undergo repression by these subregions ${ }^{12,16}$, and is highly activated even under non-stress conditions ${ }^{23}$. According to Ref. ${ }^{20}$, even when carrying the $\Delta \mathrm{I} \Delta \mathrm{V}$ mutation, Ire1 is regulated through direct recognition of unfolded proteins by the $\mathrm{CLD}^{20}$. Subregion III (see supplementary Fig. S1 for its position) is a loosely folded loop sticking out from the CLD, the deletion of which impairs the physical interaction between the cLD and unfolded protein $^{20,24}$. Since the intracellular activity of Ire1 is easily monitored using a UPRE-based reporter, from which $\beta$-galactosidase is expressed under the control of the UPRE ${ }^{25,26}$, we reproduced these findings through the UPRE-lacZ reporter assay. As shown in Fig. 1a, the activity of the reporter in unstressed cells was elevated by introduction of the $\Delta \mathrm{I} \Delta \mathrm{V}$ mutation into Ire1, and was considerably lowered when the $\Delta \mathrm{III}$ mutation was further introduced.

The initial step of this study was a screening for Ire1 mutants that intramolecularly suppress this functionless phenotype of the $\Delta \mathrm{I} \Delta \mathrm{III} \Delta \mathrm{V}$ mutation. After random mutagenesis of the IRE1 gene carrying the $\Delta \mathrm{I} \Delta \mathrm{III} \Delta \mathrm{V}$ triple deletion, as described in the Methods section, we identified an IRE1 gene thymine673-to-cytosine point mutation, which corresponds to a tyrosine225-to-histidine (Y225H) substitution, (see supplementary Fig. S1 for its position). As shown in Fig. 1a, unstressed cells carrying $\Delta \mathrm{I} \Delta \mathrm{III} \Delta \mathrm{V}$ Ire1 showed high reporter activity when it was further mutated to carry the $\mathrm{Y} 225 \mathrm{H}$ mutation. According to the X-ray crystal structure reported by Credle et al. (2005), Y225 is positioned in the $\beta-9$ sheet that forms the cLD.

We then asked if the change in the reporter values shown in Fig. 1a actually reflects the induction level of the UPR pathway. As expected, the change in the transcript abundance of $K A R 2$, which encodes $\mathrm{BiP}$ and is the most prominent UPR-target gene, exhibited a similar pattern to the result from the UPRE-lacZ reporter assay (Fig. 1a,b). Moreover, the same was observed when we checked HAC1-mRNA splicing (Fig. 1c). Meanwhile, total HAC1-mRNA abundance did not seem to be affected by the Ire1 mutations (Fig. 1d). We think that these observations are reasonable, since the main theme of the UPR signaling pathway is splicing but not transcriptional induction of HAC1 mRNA.

In the experiment shown in Fig. 2, we introduced the Y225H mutation into wild-type Ire1 and various luminal-domain mutant versions of Ire1, and checked their UPR inducibility using the UPRE-lacZ reporter. The $\mathrm{N}$-glycosylation-inhibiting antibiotic, tunicamycin, is known to impair protein folding in the ER and to induce potent ER stress. Since the reporter values of Y225H-Ire1 cells did not differ from those of wild-type-Ire1 cells under both unstressed and tunicamycin-treated conditions, we think that the $\mathrm{Y} 225 \mathrm{H}$ mutation does not largely affect the activity of wild-type Ire1. Meanwhile, the low UPR phenotype of cells carrying $\Delta \mathrm{III}$ Ire 1 or $\Delta \mathrm{I} \Delta \mathrm{III} \Delta \mathrm{V}$ Ire1 was rescued by introduction of the $\mathrm{Y} 225 \mathrm{H}$ mutation.

The UPRE-lacZ reporter assay shown in Fig. 2 also reproduced the aforementioned observation in which $\Delta \mathrm{I} \Delta \mathrm{V}$ Irel exhibits higher activity than wild-type Ire1 under non-stress conditions and is further activated by ER stress ${ }^{23}$. Importantly, the reporter activity was considerably higher in unstressed cells carrying $\Delta \mathrm{I} \Delta \mathrm{V} / \mathrm{Y} 225 \mathrm{H}$ Ire1 in comparison to those carrying $\Delta \mathrm{I} \Delta \mathrm{V}$ Ire 1, although the cellular abundance of $\Delta \mathrm{I} \Delta \mathrm{V}$ Ire1 was lowered by the $\mathrm{Y} 225 \mathrm{H}$ mutation (supplementary Fig. S2). It should also be noted that the reporter activity in cells expressing $\Delta \mathrm{I} \Delta \mathrm{V} / \mathrm{Y} 225 \mathrm{H}$ Ire1 was further elevated by cellular treatment with tunicamycin.

According to our previous observation, the ability of the cLD to physically interact with unfolded proteins is observable through in vitro analysis to monitor inhibition of unfolded-protein aggregation by the cLD ${ }^{20}$. Here, we bacterially expressed and purified N-terminal- maltose-binding protein-tagged cLD (MBP-cLD) and its mutant versions (supplementary Fig. S3), and used them in a similar assay to that described in Kimata et al. ${ }^{20}$. In the experiment shown in Fig. 3, two test proteins, citrate synthase and luciferase, were denatured in guanidine HClcontaining solution, and their aggregation was induced through dilution in an assay buffer containing MBP-cLD or its mutants. We then observed that MBP-cLD, but not the $\Delta \mathrm{III}, \mathrm{Y} 225 \mathrm{H}$, and $\Delta \mathrm{III} / \mathrm{Y} 225 \mathrm{H}$ mutants, suppressed the aggregation of denatured citrate synthase and luciferase. This observation suggests that it is unlikely that the $\mathrm{Y} 225 \mathrm{H}$ mutation suppresses the low-activity phenotype of the $\Delta \mathrm{III}$ mutation by restoring the impaired physical interaction between the cLD and unfolded proteins. Rather, the Y225H mutation seems to compromise the ability of the CLD to capture unfolded proteins.

In order to confirm this idea, we next examined the physical interaction between Irel and an ER-located model unfolded protein in S. cerevisiae cells. A mutant version of the vacuole protein carboxypeptidase Y (CPY), named $\mathrm{CPY}^{\star}$, is known to accumulate in the yeast ER without being properly folded. We previously expressed a green fluorescent protein (GFP)-tagged version of $\mathrm{CPY}^{\star}\left(\mathrm{CPY}^{\star}-\mathrm{GFP}\right)$ in S. cerevisiae cells, and found that it 
a

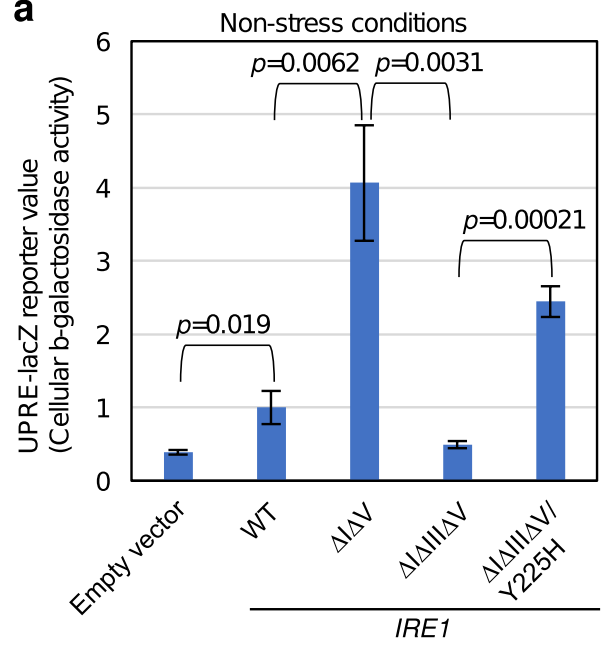

C

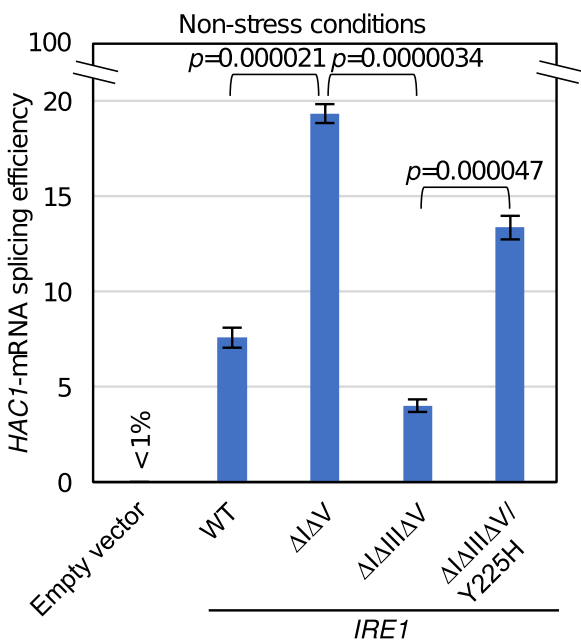

b

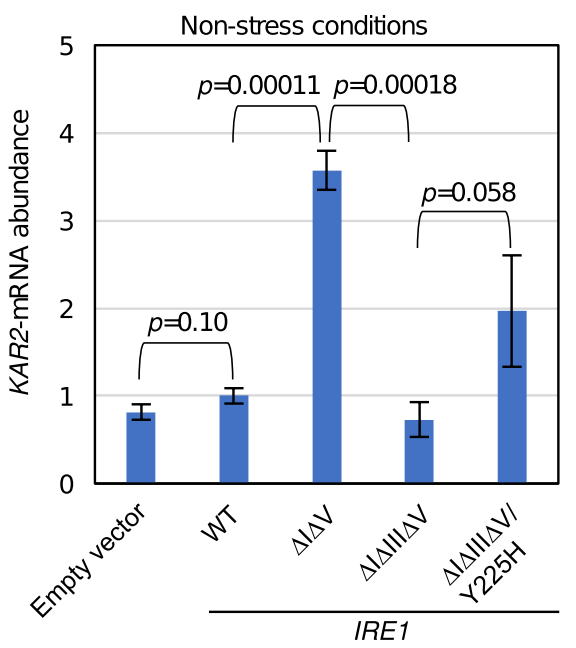

d

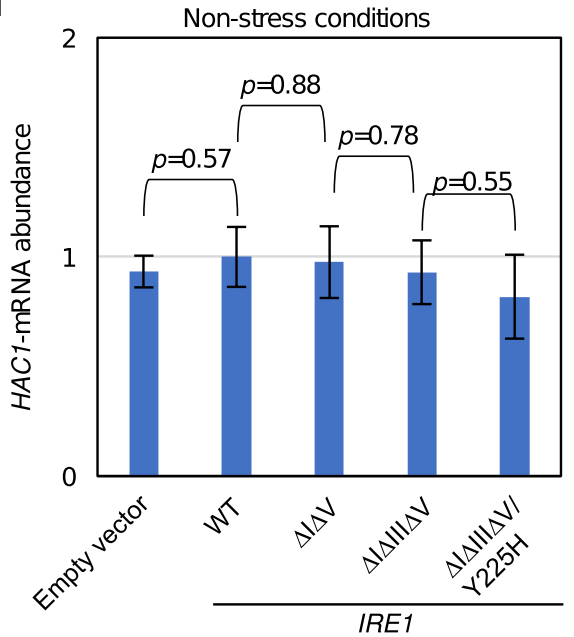

Figure 1. Isolation of the $\mathrm{Y} 225 \mathrm{H}$ mutation as an intramolecular suppressor of the low-activity phenotype of $\Delta \mathrm{I} \Delta \mathrm{III} \Delta \mathrm{V}$ Ire1. KMY1015 cells (ire1 $\Delta$ ) bearing the UPRE-lacZ reporter plasmid, pCZY1, were transformed with the IRE1 plasmid, pRS315-IRE1-HA (wild-type: WT), or with that carrying the indicated mutations (or with the empty vector, pRS315), and were grown at $30^{\circ} \mathrm{C}$ in SD medium. (a) The cultures were subjected to measurement of cellular $\beta$-galactosidase activity. (b) Total RNA samples were subjected to RT-qPCR analysis to monitor KAR2-mRNA abundance. (c) Total RNA samples were subjected to RT-PCR to monitor HAC1-mRNA splicing. (d) Total RNA samples were subjected to RT-qPCR analysis to monitor total HAC1-mRNA abundance. In panels (a), (b), and (d), the values are normalized against that of wild-type (WT) IRE1 cells, which is set at 1.0 .

is aggregated in the ER and induces the $\mathrm{UPR}^{24}$. In the experiment shown in supplementary Fig. S4, cells producing CPY*-GFP were treated with the protein crosslinker dithiobis (succinimidyl propionate) (DSP), lysed, and subjected to anti-GFP immunoprecipitation, which was followed by Western blot analysis for detection of proteins in the immunoprecipitants. The result reproduced our previous finding ${ }^{24}$, in which wild-type Ire1-HA was co-immunoprecipitated when co-expressed with $\mathrm{CPY}^{\star}$-GFP. However, such co-immunoprecipitation bands were unobservable when Ire1-HA carried either or both of the $\Delta \mathrm{III}$ and $\mathrm{Y} 225 \mathrm{H}$ mutations.

Based on these observations, we assume that the $\mathrm{Y} 225 \mathrm{H}$ mutation abolishes the requirement of a physical interaction between the cLD and unfolded proteins for activation of Ire1.

The $\Delta \mathrm{I} \Delta \mathrm{III} \Delta \mathrm{V} / \mathrm{Y} 225 \mathrm{H}$ luminal-domain mutant of Ire1 loses its responsiveness to ER stress when the cytosolic-domain kinase-inactive mutation, D797N/K799N, is introduced. The proximal function of Ire1 in the S. cerevisiae UPR is the splicing of HAC1 mRNA, which therefore serves as a finer indicator of Ire1 activation than the UPRE-lacZ reporter. Hereafter, as described previously ${ }^{24}$, we amplified HAC1 species by subjecting total RNA samples to reverse transcription (RT)-PCR and quantitatively evaluated HAC1 mRNA-splicing efficiency as described in the Methods section.

The $H A C 1$ mRNA-splicing profile of cells carrying $\Delta \mathrm{I} \Delta \mathrm{V}$ Ire1 or $\Delta \mathrm{I} \Delta \mathrm{V} / \mathrm{Y} 225 \mathrm{H}$ Ire1 (Fig. 4a) again demonstrates that the $\mathrm{Y} 225 \mathrm{H}$ mutation activates $\Delta \mathrm{I} \Delta \mathrm{V}$ Ire1 in unstressed cells. Figure $4 \mathrm{a}$ also indicates that tunicamycin 


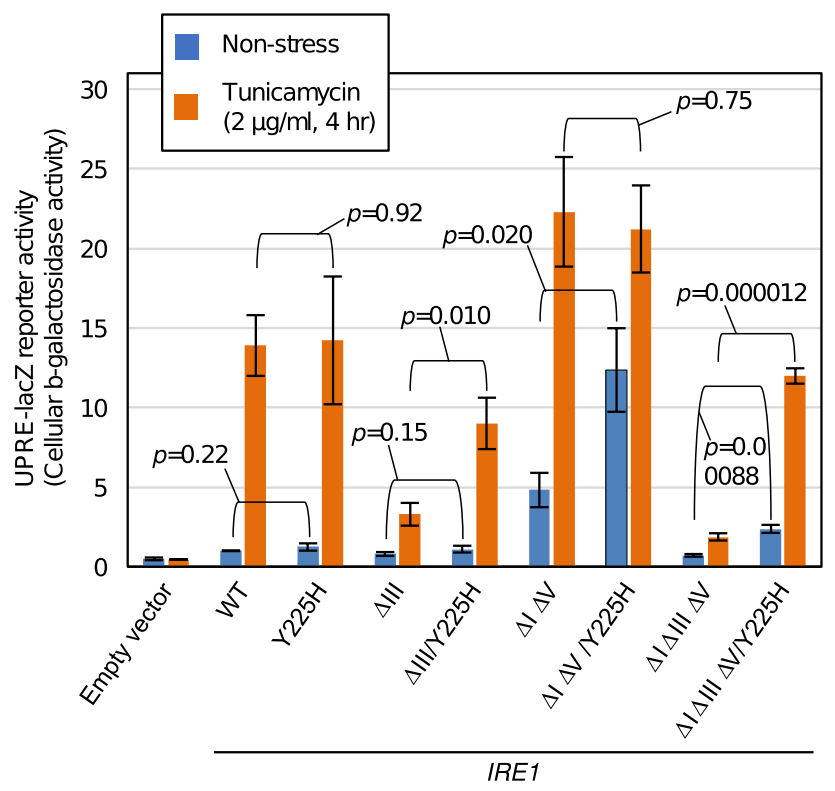

Figure 2. Effect of the Y225H mutation on the UPR inducibility of Ire1 mutants. KMY1015 cells (ire1A) bearing the UPRE-lacZ reporter plasmid, pCZY1, were transformed with the IRE1 plasmid, pRS315-IRE1-HA (wild-type: WT), or with that carrying the indicated mutations (or with the empty vector, pRS315), and were grown at $30^{\circ} \mathrm{C}$ in SD medium. For ER stress induction, we added tunicamycin $(2 \mu \mathrm{g} / \mathrm{mL})$ into the cultures, which were further cultured for $4 \mathrm{~h}$. The cultures were then subjected to the measurement of cellular $\beta$-galactosidase activity, and the resulting values are normalized against that of wild-type (WT) IRE1 cells, which is set at 1.0.
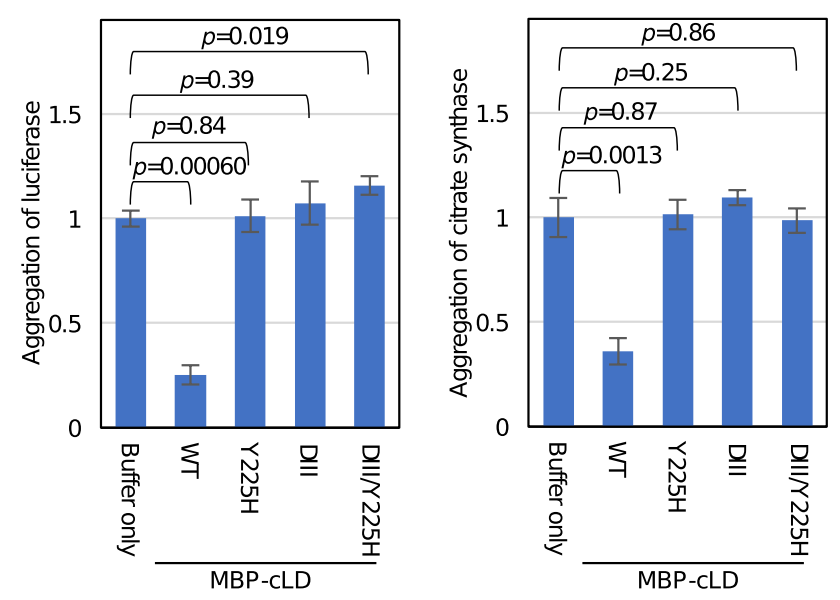

Figure 3. Effect of the $\mathrm{Y} 225 \mathrm{H}$ mutation on the physical interaction between the Irel luminal domain and unfolded proteins. After denaturation in guanidine $\mathrm{HCl}$ solution, luciferase $(25 \mu \mathrm{M})$ or citrate synthase $(50 \mu \mathrm{M})$ were 40 - (for luciferase) or 100-fold (for citrate synthase) diluted in assay buffer containing MBP-cLD (wildtype: WT) or its mutant versions ( $1 \mu \mathrm{M}$ each) or in buffer only, and further incubated at $25^{\circ} \mathrm{C}$ for $5 \mathrm{~min}$. The turbidity of the sample mixtures was then measured, normalized against that of the "Buffer only" sample, which is set at 1.0 and presented as "Aggregation".

considerably induces $H A C 1$-mRNA splicing in both $\Delta \mathrm{I} \Delta \mathrm{V}$-Ire1 cells and $\Delta \mathrm{I} \Delta \mathrm{V} / \mathrm{Y} 225 \mathrm{H}$-Ire1 cells. A similar result was obtained when we checked the cellular abundance of KAR2 mRNA (supplementary Fig. S5). As shown in Fig. $4 \mathrm{~b}, \Delta \mathrm{I} \Delta \mathrm{V} / \mathrm{Y} 225 \mathrm{H}$ Ire1 did not lose responsiveness to tunicamycin even when further mutagenized to carry the $\Delta \mathrm{III}$ mutation. Based on our observations presented thus far, we speculate that $\Delta \mathrm{I} \Delta \mathrm{V} / \mathrm{Y} 225 \mathrm{H}$ Ire 1 and $\Delta \mathrm{I} \Delta \mathrm{III} \Delta \mathrm{V} / \mathrm{Y} 225 \mathrm{H}$ Ire1 are regulated by none of the previously known regulatory events on the luminal side. We then explored the molecular basis underlying the responsiveness of $\Delta \mathrm{I} \Delta \mathrm{III} \Delta \mathrm{V} / \mathrm{Y} 225 \mathrm{H}$ Ire1 to ER stress.

The transmembrane domain of Ire1 is known to act as a sensor to monitor the membrane environment and is responsible for UPR induction upon membrane lipid-related aberrations ${ }^{27}$. While, according to Halbleib et al. and Tran et al. ${ }^{27,28}$, this property of Ire1 is abolished upon introduction of the V535R mutation (see supplementary Fig. S1 for its position), the $H A C 1$-mRNA splicing of cells expressing $\Delta \mathrm{I} \Delta \mathrm{III} \Delta \mathrm{V} / \mathrm{Y} 225 \mathrm{H} / \mathrm{V} 535 \mathrm{R}$ Ire 1 was 
a

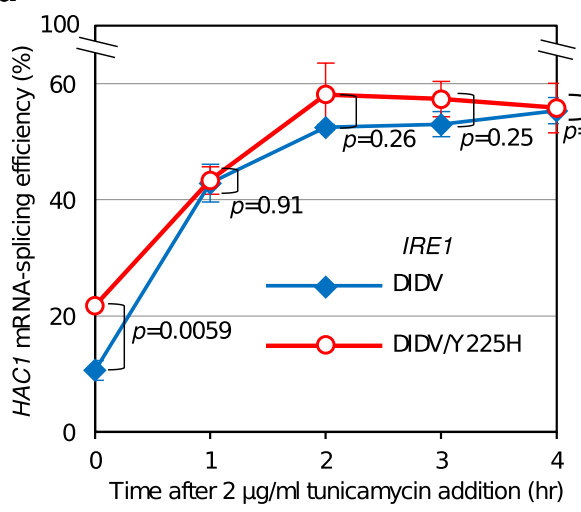

b

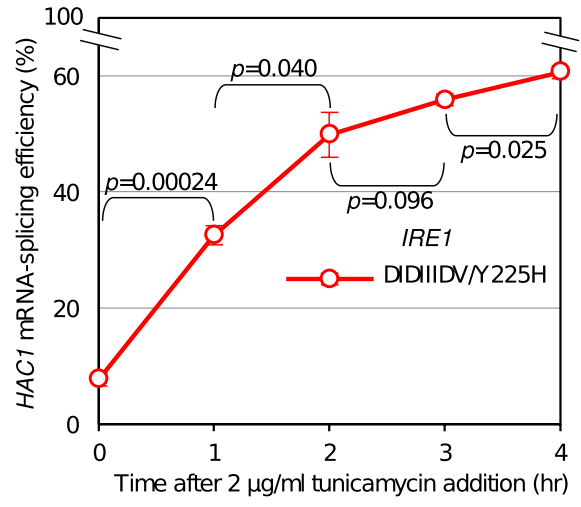

C

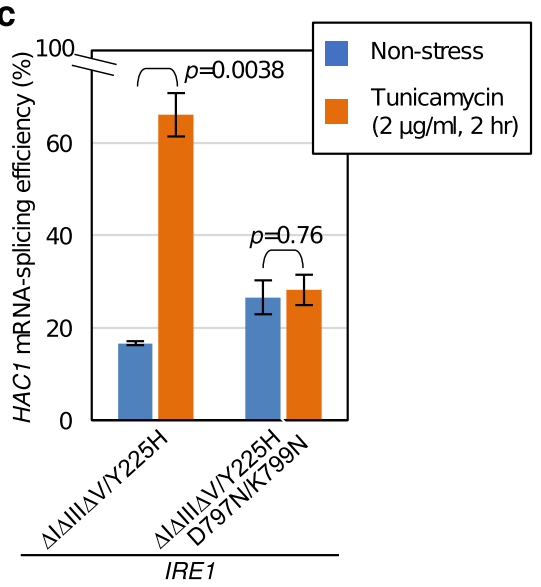

e

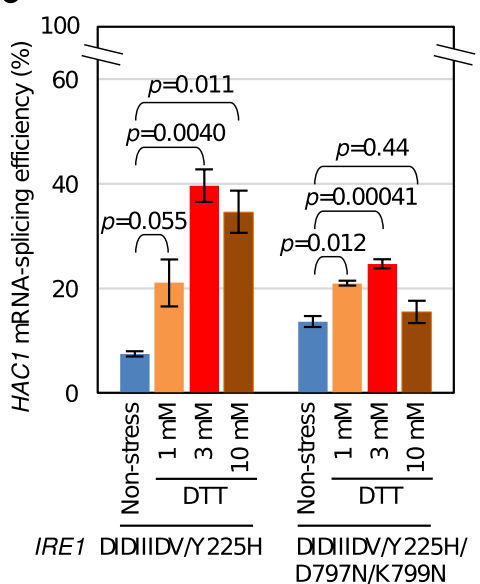

d

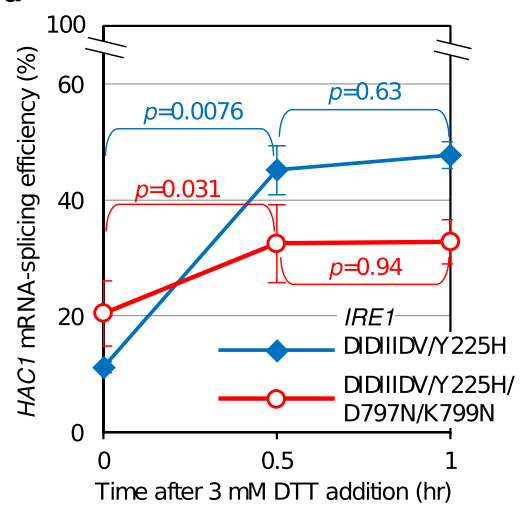

Figure 4. Effect of the D797N/K799N mutation on the ER-stress responsiveness of $\Delta \mathrm{I} \Delta \mathrm{III} \Delta \mathrm{V} / \mathrm{Y} 225 \mathrm{H}$ Ire1. After being grown at $30^{\circ} \mathrm{C}$ in SD medium, KMY 1015 cells (ire $1 \Delta$ ) carrying the indicated mutant versions of the IRE1 plasmid pRS313-IRE1 were ER-stressed and checked for HAC1-mRNA splicing efficiency using the RT-PCR technique. ( $(\mathbf{a}$ and $\mathbf{b}$ ) Cells were cultured in the presence of $2 \mu \mathrm{g} / \mathrm{mL}$ tunicamycin for the indicated durations. (c) Cells were cultured in the presence of $2 \mu \mathrm{g} / \mathrm{mL}$ tunicamycin for $2 \mathrm{~h}$ or remained unstressed. (d) Cells were cultured in the presence of $3 \mathrm{mM}$ DTT for the indicated durations. (e) Cells remained unstressed or were cultured in the presence of 1 or $3 \mathrm{mM}$ DTT for $60 \mathrm{~min}$ or $10 \mathrm{mM}$ DTT for $30 \mathrm{~min}$.

sharply induced by cellular treatment with tunicamycin (supplementary Fig. S6). It is therefore unlikely that the ER-stress responsiveness of $\Delta \mathrm{I} \Delta \mathrm{III} \Delta \mathrm{V} / \mathrm{Y} 225 \mathrm{H}$ Ire1 is based on the molecular event presented by Halbleib et al. ${ }^{27}$.

Meanwhile, $\Delta \mathrm{I} \Delta \mathrm{III} \Delta \mathrm{V} / \mathrm{Y} 225 \mathrm{H}$ Ire1 as well as wild-type Ire1 seem to be able to sense lipid-related aberrations, a prominent example of which is the depletion of inositol from yeast culture. This is because, as shown in supplementary Fig. S7, HAC1-mRNA splicing was induced upon inositol depletion in cells carrying $\Delta \mathrm{I} \Delta \mathrm{III} \Delta \mathrm{V} /$ 


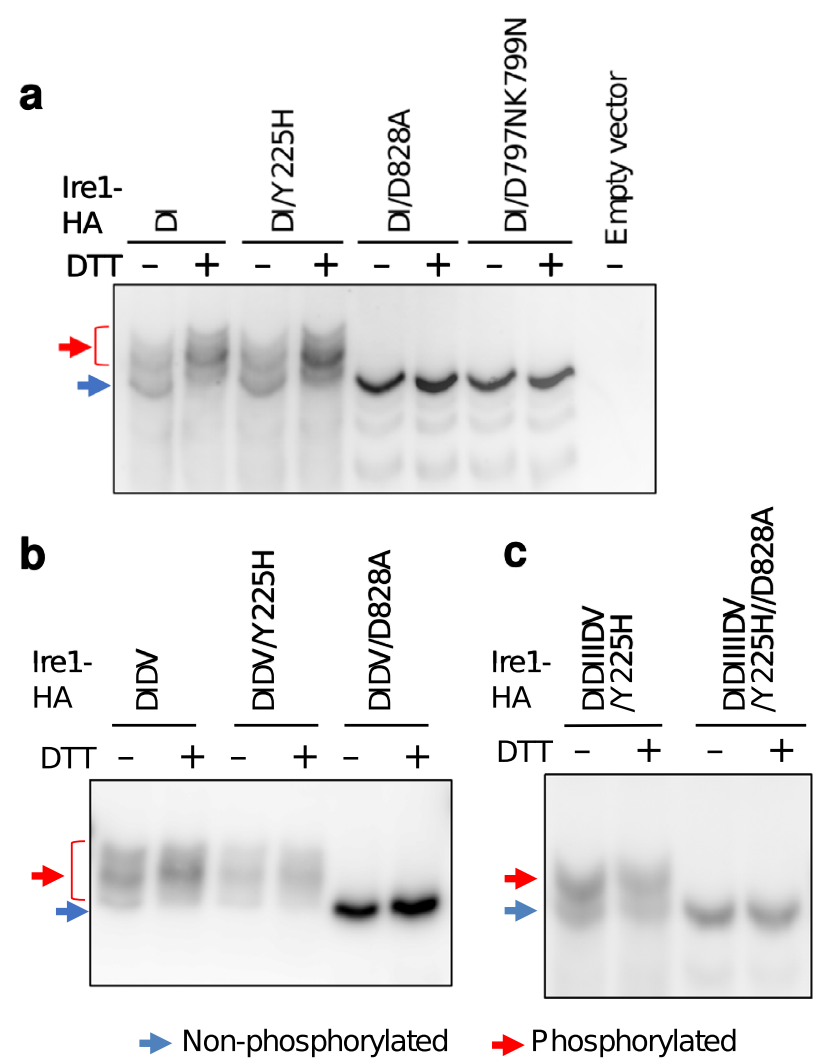

Figure 5. Effect of the Ire1 mutations on its phosphorylation status. After being grown at $30^{\circ} \mathrm{C}$ in $\mathrm{SD}$ medium, KMY1015 cells (ire1A) carrying the indicated mutant versions of the Ire1-HA-expression plasmid, pRS315IRE1-HA, were cultured in the presence of DTT $(10 \mathrm{mM}, 30 \mathrm{~min})$ or remained unstressed. Lysates of cells (equivalent to $\mathrm{OD}_{600}=0.25$ ) were then analyzed by Phos-tag SDS-PAGE and anti-HA Western blotting. The uncropped blots are presented in supplementary Fig. S12.

Y225H Ire1 or wild-type Ire1. As expected, the V535R mutation compromised the HAC1-mRNA splicing induced by inositol depletion.

According to Rubio et al. ${ }^{29}$, Ire1 is activated without autophosphorylation or binding to ADP when carrying the kinase-inactive mutation D797N/K799N (see supplementary Fig. S1 for its position). As shown in supplementary Fig. S8a, D797N/K799N Ire1 was strictly controlled by ER stress and was upregulated by tunicamycin, although slightly weaker than wild-type Ire1. Meanwhile, in the case of cells carrying $\Delta \mathrm{I} \Delta \mathrm{III} \Delta \mathrm{V} / \mathrm{Y} 225 \mathrm{H}$ Ire1, the HAC1-splicing efficiency in unstressed cells was increased by introduction of the D797N/K799N mutation (Fig. 4c; Non-stress). Figure $4 \mathrm{c}$ also shows that the responsiveness of $\Delta \mathrm{I} \Delta \mathrm{III} \Delta \mathrm{V} / \mathrm{Y} 225 \mathrm{H}$ Ire 1 to tunicamycininduced ER stress was almost completely abolished by the D797N/K799N mutation.

The thiol-reducing reagent, dithiothreitol (DTT), is also known to impair protein folding in the ER and cause ER stress when applied into yeast cultures. As well as wild-type-Ire 1 cells, cells carrying either $\Delta \mathrm{I} \Delta \mathrm{III} \Delta \mathrm{V} /$ Y225H Ire1 or D797N/K799N Ire1 sharply elevated their HAC1-mRNA splicing efficiency in response to DTT exposure (Fig. 4d, e, and supplementary Figs S8b and S9). Meanwhile, when the $\Delta \mathrm{I} \Delta \mathrm{III} \Delta \mathrm{V} / \mathrm{Y} 225 \mathrm{H}$ mutation and the D797N/K799N mutation were combined ( $\Delta \mathrm{I} \Delta \mathrm{III} \Delta \mathrm{V} / \mathrm{Y} 225 \mathrm{H} / \mathrm{D} 797 \mathrm{~N} / \mathrm{K} 799 \mathrm{~N}$-Irel cells), the response to DTT exposure was marginal (Fig. 4d, e, and supplementary Fig. S9).

We therefore assume that the responsiveness of $\Delta \mathrm{I} \Delta \mathrm{III} \Delta \mathrm{V} / \mathrm{Y} 225 \mathrm{H}$ Ire1 to ER stress is based on the functions of the kinase region of Ire1, which is autophosphorylation and ADP capture.

The $\Delta \mathrm{I} \Delta \mathrm{V}$ mutation leads to autophosphorylation of Ire1 even in unstressed cells. Phos-tag is an artificial molecule that specifically captures phosphorylated species. On sodium dodecyl sulfate-polyacrylamide gel electrophoresis using Phos-tag-bound polyacrylamide (Phos-tag SDS-PAGE), the migration of phosphorylated proteins is considerably retarded. In order to determine the phosphorylation status of Irel tagged with the HA epitope (Ire1-HA), cell lysates were fractionated by Phos-tag SDS-PAGE, which was followed by anti-HA immunoblotting (Fig. 5). In this experiment, cells were ER-stressed with DTT but not with tunicamycin. This is because tunicamycin inhibits N-glycosylation and thus changes the migration of N-glycosylated proteins, such as Ire1, on SDS-PAGE gels independent of their phosphorylation status.

As described in the Methods section, we did not use the metalloprotease inhibitor, ethylenediaminetetraacetic acid (EDTA), when we lysed cells for the Phos-tag SDS-PAGE analysis, because EDTA inhibits the function of Phos-tag to bind to phosphoproteins. Therefore, wild-type Ire1-HA is partially cleaved at Subregion I during cell lysis, causing its complicated band pattern on Phos-tag SDS-PAGE ${ }^{30}$. In the experiment shown in Fig. 5a, we 
therefore used cells producing $\Delta \mathrm{I}$ Ire1-HA or its point mutants instead of those producing wild-type Ire1-HA or its point mutants. It should be noted that the stress responsiveness of $\Delta \mathrm{I}$ Ire 1 and $\Delta \mathrm{I} / \mathrm{Y} 225 \mathrm{H}$ Ire 1 did not largely differ from that of wild-type Ire1 and Y225H Ire1 (supplementary Fig. S9). As shown in Fig. 5a, migration of $\Delta \mathrm{I}$ Ire1 on Phos-tag SDS-PAGE was diminished upon stressing of cells with DTT. However, such a shift in migration was not observed when Irel carried the kinase-inactive mutation D828A, namely the non-phosphorylated control. When enzymatically dephosphorylated before Phos-tag SDS-PAGE, $\triangle \mathrm{I}$ Ire1-HA appeared as a sharp singlet band, the migration of which was the same as that of D828A Ire1-HA (supplementary Fig. S10a). No bands were detected from a sample not containing an HA-tagged version of the Irel variants (Fig. 5a and supplementary Fig. S10a). We thus assume that, as presented in Ishiwata-Kimata et al. ${ }^{30}$, this method allowed us to monitor the autophosphorylation of Ire1.

Since $\mathrm{Y} 225 \mathrm{H} / \Delta \mathrm{I}$ Ire1-HA exhibited a similar migration shift upon cellular treatment with DTT to that of $\Delta \mathrm{I}$ Ire1-HA (Fig. 5a), it is unlikely that the Y225H mutation affects the autophosphorylation status of Ire1. Figure 5a also indicates that $\triangle \mathrm{I}$ Ire1-HA carrying the D797N/K799N mutation remained non-phosphorylated even in the presence of ER stress. This observation is consistent with Rubio et al. $^{29}$, who argued that D797N/K799N Ire1 has the ability to promote $H A C 1$-mRNA splicing even though it cannot be autophosphorylated.

Meanwhile, $\Delta \mathrm{I} \Delta \mathrm{V}$ Ire1-HA or $\Delta \mathrm{I} \Delta \mathrm{V} / \mathrm{Y} 225 \mathrm{H}$ Ire1-HA did not change their migration upon DTT stress (Fig. 5b), although they were upregulated to splice the HAC1 mRNA under this stress condition (supplementary Fig. S9). In addition to $\Delta \mathrm{I}$ Ire1-HA, $\Delta \mathrm{I} \Delta \mathrm{V}$ Ire1-HA appears as a sharp singlet band when carrying the D828A mutation or enzymatically dephosphorylated before Phos-tag SDS-PAGE (Fig. 5b and supplementary Fig. S10b). We therefore assume that the $\Delta \mathrm{I} \Delta \mathrm{V}$ mutation caused the constitutive autophosphorylation of Ire1. A diffused band pattern of $\Delta \mathrm{I} \Delta \mathrm{III} \Delta \mathrm{V} / \mathrm{Y} 225 \mathrm{H}$ Ire1-HA is also likely to indicate its autophosphorylation (supplementary Fig. $\mathrm{S} 10 \mathrm{~b})$. Figure $5 \mathrm{c}$ shows that the autophosphorylation status of $\Delta \mathrm{I} \Delta \mathrm{III} \Delta \mathrm{V} / \mathrm{Y} 225 \mathrm{H}$ Ire1-HA was almost unaffected by ER stress.

Based on their amino-acid sequences, the sizes of $\Delta \mathrm{I}$ Ire1-HA, $\Delta \mathrm{I} \Delta \mathrm{V}$ Ire1-HA, and $\Delta \mathrm{I} \Delta \mathrm{III} \Delta \mathrm{V} / \mathrm{Y} 225 \mathrm{H}$ Ire $1-\mathrm{HA}$ are $120 \mathrm{kDa}, 113 \mathrm{kDa}$, and $111 \mathrm{kDa}$, respectively. Their migration and point mutants on normal SDS-APGE were almost consistent with the migration of the molecular weight marker (supplementary Fig. S11).

Activity of $\Delta \mathrm{I} \Delta \mathrm{III} \Delta \mathrm{V} / \mathrm{Y} 225 \mathrm{H}$ Ire1 is likely to be linked to levels of cellular ADP. While, according to our observations from the D797N/K799N mutation (Fig. 4c,d,e, and supplementary Fig. S9), $\Delta \mathrm{I} \Delta \mathrm{III} \Delta \mathrm{V} /$ Y225H Ire1 is likely to be regulated through autophosphorylation and/or ADP capture, the autophosphorylation status of $\Delta \mathrm{I} \Delta \mathrm{III} \Delta \mathrm{V} / \mathrm{Y} 225 \mathrm{H}$ Ire1 was not regulatory but was constitutive (Fig. $5 \mathrm{c}$ ). We thus speculate that the ERstress responsiveness of $\Delta \mathrm{I} \Delta \mathrm{III} \Delta \mathrm{V} / \mathrm{Y} 225 \mathrm{H}$ Ire1 is due to its ADP capture. A hypothesis arising from this idea is that $\Delta \mathrm{I} \Delta \mathrm{III} \Delta \mathrm{V} / \mathrm{Y} 225 \mathrm{H}$ Ire1 is regulated not by ER accumulation of unfolded proteins per se but by the cytosolic level of ADP.

In the experiment shown in Fig. 6a, cells were lysed and subjected to a biochemical assay for monitoring of the ADP/ATP ratio. We observed that potent ER-stressing stimuli that strongly activate $\Delta \mathrm{I} \Delta \mathrm{III} \Delta \mathrm{V} / \mathrm{Y} 225 \mathrm{H}$ Ire 1 , namely treatment of cells with 3 or $10 \mathrm{mM}$ DTT or $2 \mu \mathrm{g} / \mathrm{mL}$ tunicamycin, increased the cellular ADP/ATP ratio, although moderately. We did not stress cells with $10 \mathrm{mM}$ DTT for $1 \mathrm{~h}$, because under this condition, cells died quite pronouncedly. Throughout this study, we did not use low concentrations of tunicamycin to induce weak ER stress because, unlike DTT, tunicamycin seems to have a severe threshold concentration to exert any biological effect. On the other hand, we can easily induce weak ER stress by using low concentrations of DTT. Figure 6a also shows that the cellular ADP/ATP ratio was almost unaffected by weak ER stress induced by 1 mM DTT.

We next asked if $\Delta \mathrm{I} \Delta \mathrm{III} \Delta \mathrm{V} / \mathrm{Y} 225 \mathrm{H}$ Ire1 is upregulated by a stress stimulus that does not significantly induce ER stress but does highly affect the cellular ADP/ATP ratio. As confirmed in Fig. 6a, sodium azide is known to lead to an increase in the cellular ADP/ATP ratio through inhibition of mitochondrial respiration and other cellular processes ${ }^{31}$. As shown in Fig. $6 \mathrm{~b}$, azide treatment induced $H A C 1$ splicing in cells carrying $\Delta \mathrm{I} \Delta \mathrm{III} \Delta \mathrm{V} /$ Y225H Ire1 but not in cells carrying wild-type Ire1 or $\Delta \mathrm{I} \Delta \mathrm{III} \Delta \mathrm{V} / \mathrm{Y} 225 \mathrm{H} / \mathrm{D} 797 \mathrm{~N} / \mathrm{K} 799 \mathrm{~N}$ Ire1.

In the experiment shown in Fig. 6c, d, cells carrying wild-type Ire1 were dually stressed by $1 \mathrm{mM}$ DTT, which minimally changed the cellular ADP/ATP ratio (see Fig. 6a), and sodium azide. Strikingly, the dual-stressing stimuli considerably induced HAC1-mRNA splicing. We assume that, as described in the Discussion section, this observation can be explained by our argument that Irel is dually regulated on the luminal and cytosolic sides. Namely, weak ER stress induced by $1 \mathrm{mM}$ DTT "turns on" the regulatory machinery of Ire1 on the luminal side, whereas sodium azide "turns on" the regulatory event on the cytosolic side by changing the cellular ADP/ ATP ratio.

One criticism against this scenario is that azide exposure can be a weak ER-stressing stimulus, which may lead to potent ER stress when combined with $1 \mathrm{mM}$ DTT. In order to address this issue, we performed an experiment as shown in Fig. 6e. Potent ER-stressing stimuli are known to commonly damage ire 1 $\Delta$ cells more severely than wild-type IRE $1+$ cells $^{32,33}$. This was reproduced in our experiment shown in Fig. 6e, in which ire $1 \Delta$ cells drastically lost their colony-forming ability when strongly ER-stressed by DTT $(3 \mathrm{mM}, 3 \mathrm{hr})$ or tunicamycin $(2 \mu \mathrm{g} / \mathrm{mL}, 3 \mathrm{~h})$. A modest decline in colony-forming ability was also observed when ire $1 \Delta$ cells were stressed by $1 \mathrm{mM}$ DTT for $3 \mathrm{~h}$. Meanwhile, $0.01 \%$ sodium azide alone did not seem to affect the colony-forming ability of wild-type IRE1 cells or ire $1 \Delta$ cells. More importantly, azide exposure did not decrease the colony-forming ability of ire $1 \Delta$ cells even in the presence of $1 \mathrm{mM} \mathrm{DTT}$, suggesting that the combination of azide and $1 \mathrm{mM}$ DTT did not aggravate ER stress. We therefore assume that the potent activation of Ire1 in cells concurrently exposed to azide and $1 \mathrm{mM}$ DTT (Fig. 6d) is not a simple reflection of their ER-stressing status. However, we cannot completely exclude the possibility that azide may induce an imperceptible ER stress, which leads to the activation of a highly sensitive Ire1 variant, $\Delta \mathrm{I} \Delta \mathrm{III} \Delta \mathrm{V} / \mathrm{Y} 225 \mathrm{H}$ Ire1. 
Figure 6. Possible relationship between cellular ADP/ATP ratio and activation of Ire1. (a) After being grown at $30^{\circ} \mathrm{C}$ in SD medium, KMY1015 cells (ire1 $\Delta$ ) carrying the wild-type IRE1 plasmid, pRS313-IRE1, were further cultured under the indicated stress conditions, and were checked for the cellular ADP/ATP ratio. (b) After being grown at $30^{\circ} \mathrm{C}$ in SD medium, KMY1015 cells (ire1A) carrying the IRE1 plasmid, pRS313-IRE1 (wildtype: WT), or its mutants were further cultured in the presence or absence of $0.01 \% \mathrm{NaN}_{3}$ for $2 \mathrm{~h}$, and were checked for the HAC1 mRNA-splicing efficiency using the RT-PCR technique. (c) Procedure for dual stressing of cells with dilute DTT and sodium azide. (d) KMY1015 cells (ire1A) carrying the wild-type (WT) IRE1 plasmid, pRS313-IRE1, were dually stressed as illustrated in panel C, and were checked for the HAC1 mRNAsplicing efficiency (rightmost column). Alternatively, the cells were treated with either or none of the reagents. (e) KMY1015 cells (ire1A) carrying the wild-type IRE1 plasmid pRS313-IRE1 ("WT IRE1" cells) or the empty vector pRS313 ("ire 1 $\Delta^{\prime \prime}$ cells) were incubated at $30^{\circ} \mathrm{C}$ in SD medium in the presence of the indicated chemicals for $3 \mathrm{~h}$. The cultures were then adjusted to $\mathrm{OD}_{600}=0.3$, serially diluted, and plated on normal SD agar plates, which were incubated for 3 days after which the number of colonies was counted. For the non-stress control, unstressed cultures were similarly treated. The colony-forming unit of each sample is normalized against that of the non-stress control, which is set at 100 and expressed as "Survival (\%)".

Weak ER stress inappropriately activates D797N/K799N Ire1. In order to explore the physiological meaning of the kinase-domain-dependent regulation of Ire1 more deeply, we finally performed a phenotypic comparison between the wild-type IRE1 cells and D797N/K799N mutant cells. As shown in Fig. 7a, HAC1 mRNA-splicing efficiency in cells carrying wild-type Ire1 was increased in a DTT concentration-dependent manner, while D797N/K799N Ire1 cells stressed by 1 mM DTT exhibited high HAC1 mRNA-splicing efficiency, which was not enhanced by elevating DTT concentration. This observation again argues for the direct involvement of the kinase region in responsiveness of Ire1 to ER-stressing stimuli.

Figure $7 \mathrm{~b}$ shows that the growth of cells producing D797N/K799N Ire1 was slightly retarded in comparison to that of wild-type Ire 1 cells when they were exposed to $1 \mathrm{mM}$ DTT. It should be noted that, even 3-h after stress onset, the D797N/K799N mutation enhanced the efficiency of HAC1-mRNA splicing induced by cellular treatment with $1 \mathrm{mM} \mathrm{DTT} \mathrm{(Fig.} \mathrm{7c).} \mathrm{We} \mathrm{therefore} \mathrm{assume} \mathrm{that} \mathrm{improperly} \mathrm{strong} \mathrm{evocation} \mathrm{of} \mathrm{the} \mathrm{UPR} \mathrm{leads} \mathrm{to}$ growth retardation of D797N/K799N-Ire1 cells under the $1 \mathrm{mM}$ DTT condition.

\section{Discussion}

In general terms, the luminal domain of Irel serves as the regulatory unit, which controls RNase activity of the cytosolic domain in response to ER stress. Meanwhile, $\Delta \mathrm{I} \Delta \mathrm{III} \Delta \mathrm{V} / \mathrm{Y} 225 \mathrm{H}$ Ire1 still responded to ER stress, although we assume that this mutant is controlled independently of the molecular events on the luminal side (Figs. 1, 2 and 3). Because the stress responsiveness of $\Delta \mathrm{I} \Delta \mathrm{III} \Delta \mathrm{V} / \mathrm{Y} 225 \mathrm{H}$ Ire1 was almost completely abolished by the kinase-region mutation, D797N/K799N, we deduce that, in addition to the luminal domain, the kinase region per se contributes to the stress responsiveness of Ire1 (Fig. 4).

One of the roles of the kinase region is the autophosphorylation of Ire1, which is abolished by the D797N/ K799N mutation (Fig. 5a; Ref. ${ }^{29}$ ). The autophosphorylation of Ire1 occurs in response to ER stress ${ }^{30}$ and contributes to the activation of Ire1 as an $\mathrm{RNase}^{7,8}$. Nevertheless, we do not think that the stress responsiveness of $\Delta \mathrm{I} \Delta \mathrm{III} \Delta \mathrm{V} / \mathrm{Y} 225 \mathrm{H}$ Ire1 is directly linked to its autophosphorylation, because Ire1 variants carrying the $\Delta \mathrm{I} \Delta \mathrm{V}$ mutation are constitutively autophosphorylated (Fig. 5). Wild-type Ire1 self-associates in an ER-stress dependent manner, while the self-association of $\Delta \mathrm{I} \Delta \mathrm{V}$ Ire 1 is constitutive ${ }^{13}$. Therefore, we deduce that Ire 1 is automatically autophosphorylated when it self-associates.

The other role of the kinase region is to capture ADP, which serves as an activation ligand for Ire ${ }^{8-10}$. Since the kinase domain does not function in phosphotransfer in this case, as initially presented by Papa et al. ${ }^{34}$, nonhydrolyzable nucleotide analogs can function positively for activation of Ire1 or its mutants. Because the D797N/ K799N mutation also eliminates the requirement of this process for activation of Ire $1^{29}$, we hypothesize that the stress responsiveness of $\Delta \mathrm{I} \Delta \mathrm{III} \Delta \mathrm{V} / \mathrm{Y} 225 \mathrm{H}$ Ire1 is based on its interaction with ADP. In agreement with this idea, $\Delta \mathrm{I} \Delta \mathrm{III} \Delta \mathrm{V} / \mathrm{Y} 225 \mathrm{H}$ Ire1 was upregulated by cellular treatment with sodium azide, which inhibits ATP production but does not seem to act as an ER stressor (Fig. 6b). Moreover, our observation in Fig. 6a demonstrates an increase in the cytosolic ADP/ATP ratio alongside potent ER-stressing stimuli, although moderately.

One ATP molecule bound to Ire1 is converted to ADP upon its autophosphorylation. We speculate that this ADP molecule is quickly exchanged with free cytosolic ATP for further autophosphorylation of Ire1, since multiple amino-acid residues are targeted by the Ire1 autophosphorylation ${ }^{7}$. At least in the case of S. cerevisiae cells, no report has described phosphorylation of other proteins by Ire1, suggesting that ATP is not hydrolyzed to $\mathrm{ADP}$ by the already phosphorylated Ire1 homo-complex. It should be also noted that the in vitro experiments reported by Korennykh et al. ${ }^{10}$ argue that ADP and ATP are captured by the nucleotide-binding pocket of Ire1 with similar affinities, while ADP works far more effectively than ATP as the activation ligand. Thus ATP should serve as a competitive inhibitor of ADP. Based on these insights, we deduce that the kinase region of Ire1 functions as a sensor for the cytosolic ADP/ATP ratio.

Nevertheless, the stress responsiveness of $H A C 1$ mRNA splicing by $\Delta \mathrm{I} \Delta \mathrm{III} \Delta \mathrm{V} / \mathrm{Y} 225 \mathrm{H}$ Ire 1 may not be explained solely by the function of the kinase region. As shown in Fig. 4d, e, DTT seemed to upregulate $\Delta \mathrm{I} \Delta \mathrm{III} \Delta \mathrm{V} / \mathrm{Y} 225 \mathrm{H} / \mathrm{D} 797 \mathrm{~N} / \mathrm{K} 799 \mathrm{~N}$ Ire1, albeit not sharply. Moreover, the HAC1 mRNA-splicing efficiency of $\Delta \mathrm{I} \Delta \mathrm{III} \Delta \mathrm{V} / \mathrm{Y} 225 \mathrm{H}$ Ire1 in azide-treated cells was not as high as that in cells stressed by conventional ER stressors (compare Figs. 4, 5, 6b), although azide treatment elevated the cellular ADP/ATP ratio more drastically than the ER-stressing stimuli (Fig. 6a). Further studies are required to understand the molecular basis underlying these observations. 
a

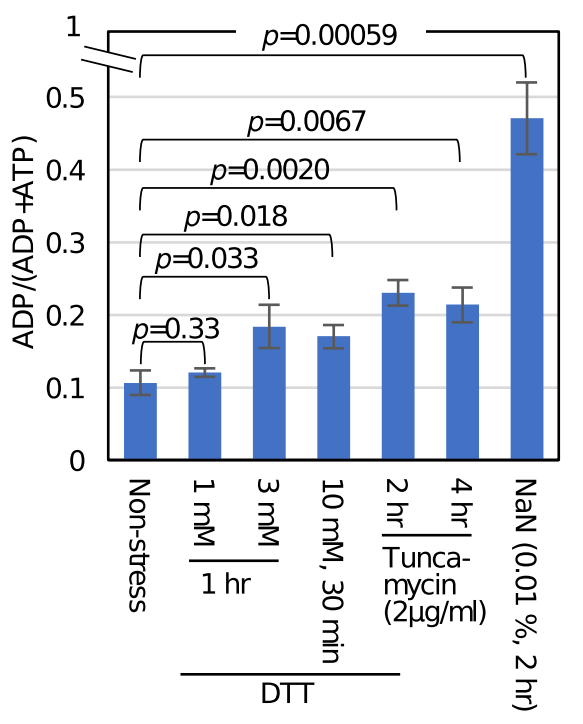

C Cell culture in SD medium
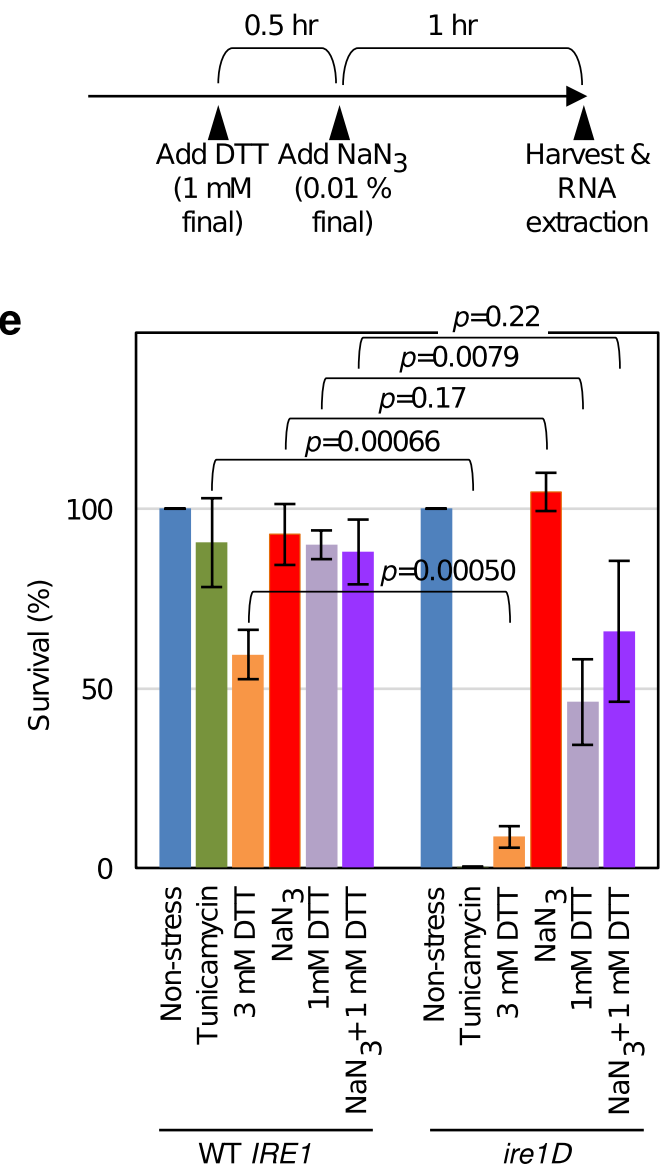

b

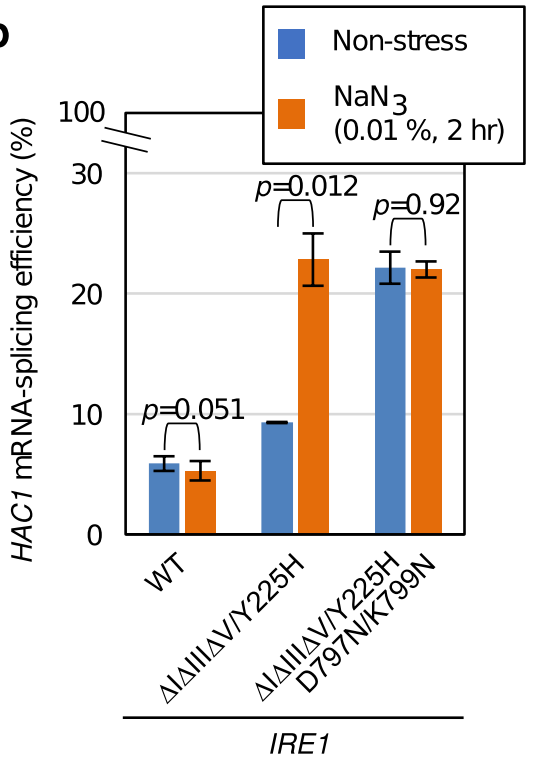

d

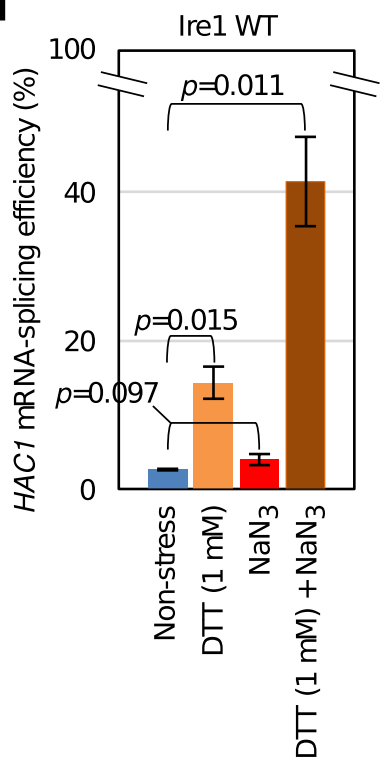

Tunicamycin: $2 \mu \mathrm{g} / \mathrm{ml}$

$\mathrm{NaN}_{3}: 0.01 \%$ 
a

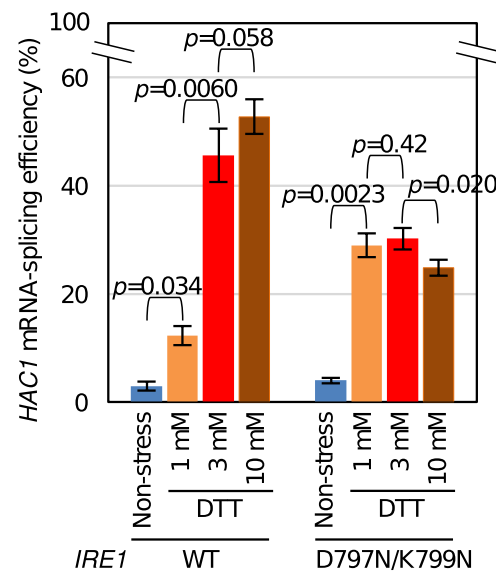

C

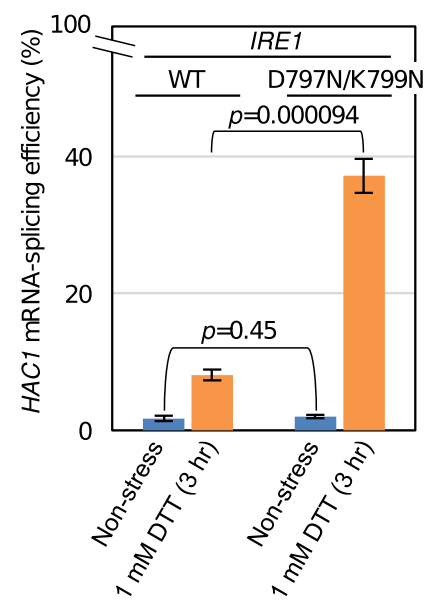

b

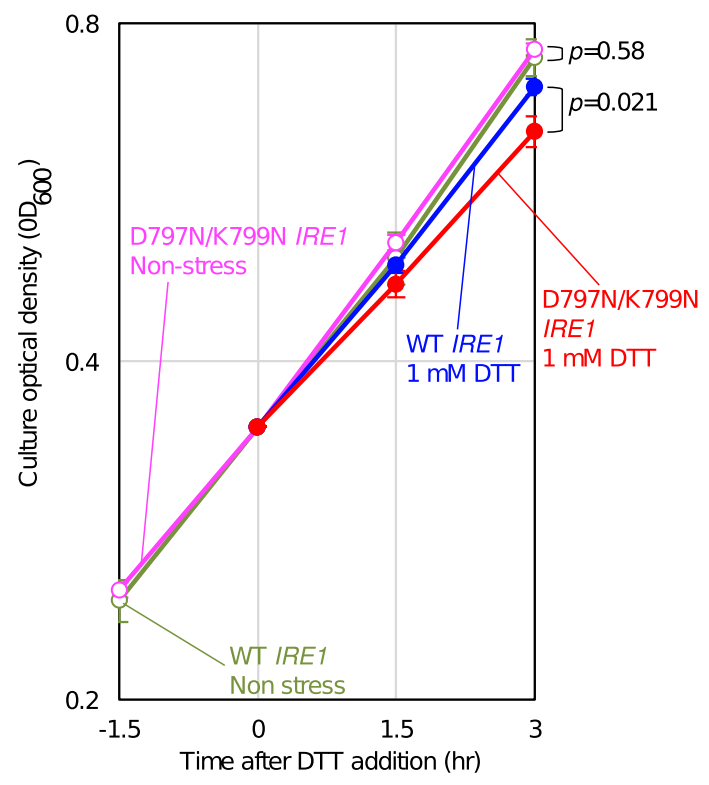

Figure 7. Stress sensitivity of cells carrying either wild-type Ire1 or its D797N/K799N mutant. After being grown at $30^{\circ} \mathrm{C}$ in SD medium, KMY1015 cells (ire1 $\Delta$ ) carrying the IRE1 plasmid, pRS313-IRE1 (wild-type: $\mathrm{WT}$ ), or its D797N/K799N mutant were stressed as follows or remained unstressed. (a) Cells were cultured in the absence or presence of DTT ( 1 or $3 \mathrm{mM}$ for $1 \mathrm{~h}$ or $10 \mathrm{mM}$ for $30 \mathrm{~min}$ ), and were checked for HAC1 mRNAsplicing efficiency using the RT-PCR technique. (b) Optical density $\left(\mathrm{OD}_{600}\right)$ of the cultures was monitored at the indicated time points. For stress imposition, $1 \mathrm{mM} \mathrm{DTT}$ was added into cultures at time 0 . The values are normalized against that of time 0 , which is set at 0.350 . (c) Cells were cultured in the absence or presence of $1 \mathrm{mM}$ DTT for $3 \mathrm{~h}$, and were checked for HAC1 mRNA-splicing efficiency using the RT-PCR technique.

It should be also noted that, according to our observations presented here (Figs. 4 and $7 \mathrm{a}$, and supplementary Figs S8 and S9) and a previous observation by others ${ }^{29}$, introduction of the D797N/K799N mutation lowers the $H A C 1 \mathrm{mRNA}$-splicing efficiency of fully activated wild-type Ire 1 and $\Delta \mathrm{I} \Delta \mathrm{III} \Delta \mathrm{V} / \mathrm{Y} 225 \mathrm{H}$ Ire1. This observation is consistent with in vitro biochemical experiments performed by Korennykh et al. ${ }^{10}$, which argues that the RNAcleavage activity of the Ire 1 cytosolic recombinant fragment is compromised by the D797N/K799N mutation.

Unlike $\Delta \mathrm{I} \Delta \mathrm{III} \Delta \mathrm{V} / \mathrm{Y} 225 \mathrm{H} / \mathrm{D} 797 \mathrm{~N} / \mathrm{K} 799 \mathrm{~N}$ Ire1, $\Delta \mathrm{I} \Delta \mathrm{III} \Delta \mathrm{V} / \mathrm{Y} 225 \mathrm{H}$ Ire1 and D797N/K799N Ire1 responded sharply to ER stress (Figs. 4 and 7, and supplementary Figs S8 and S9), suggesting that wild-type Ire1 is dually regulated by ER conditions per se and the cytosolic ADP/ATP ratio. Unlike wild-type Ire1, D797N/K799N Ire1, which bypasses regulation by the kinase region, seems to be fully activated even upon weak ER stress, by which the cellular ADP level is not largely affected (Figs. 6a and 7a). Moreover, wild-type Ire1 was strongly activated when cells were dually stressed by $1 \mathrm{mM}$ DTT (weak ER stress) and sodium azide (Fig. 6c, d). We thus propose the following scenario, which is illustrated in Fig. 8, to explain how ER stress leads to activation of Irel as an RNase in S. cerevisiae cells. Upon ER stress, Ire1 self-associates as it is released from suppression by Subregion $\mathrm{V}$, which serves as the BiP-binding site, and by Subregion ${ }^{23}$. Subsequently, the self-associated Ire1 molecules are automatically autophosphorylated and directly capture ER-accumulated unfolded proteins ${ }^{20,21}$. Moreover, potent ER stress increases the cytosolic ADP/ATP ratio, which is monitored by the kinase region of Ire1, leading to full activation of Ire1.

How does ER stress increase the cytosolic ADP/ATP ratio? Since, as commonly accepted, potent ER stress considerably harms cells, we may not have to assume a sophisticated mechanism. When cells are heavily ERstressed, they become unhealthy, and various cellular systems may be damaged, which eventually leads to 


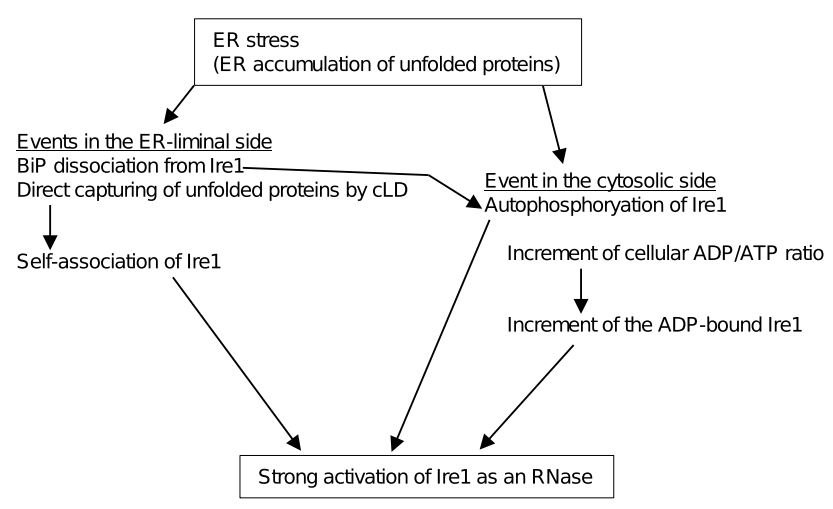

Figure 8. Our model for activation of Ire1 in response to ER stress. On the ER-luminal side, unfolded proteins cause dissociation of $\mathrm{BiP}$ from Ire1. Moreover, Ire1 directly captures unfolded proteins. These events cause self-association of Ire1. On the cytosolic side, BiP-unbound and dimerized Ire1 molecules are automatically autophosphorylated. Moreover, potent ER stress increases the cellular ADP/ATP ratio. This also contributes to the activation of Ire1, because ADP serves as an activation ligand of Ire1.

impairment of ATP production. In other words, Ire1 is regulated not only by ER conditions but also by the overall "vividness" of cells, which is reflected by the cytosolic ADP/ATP ratio.

The Ire1-HAC1 pathway of the UPR is known to control a number of genes in S. cerevisiae cells ${ }^{4,5}$. Furthermore, when inappropriately induced, the UPR harms cells ${ }^{29,35}$. Therefore, it seems rational that the UPR remains only weak when ER stress is not potent enough to inhibit ATP biosynthesis. This idea explains the physiological meaning of Ire1 regulation by the cytosolic ADP/ATP ratio. In agreement with this idea, cells carrying D797N/ K799N Ire1 exhibited higher HAC1-mRNA splicing and retarded growth in comparison to wild-type IRE1 cells when weakly ER-stressed by 1 mM DTT (Fig. 7).

It should also be noted that HAC1-mRNA splicing was poorly induced by treatment of wild-type IRE1 cells with sodium azide alone (Fig. 6b, d). Moreover, sodium azide did not seem to induce death of wild-type and ire $1 \Delta$ cells (Fig. 6e). Therefore, we do not think that the Ire1-HAC1 pathway of the UPR is a cellular response that copes with ATP biogenesis defects. An increment of the cytosolic ADP/ATP ratio alone is unlikely to activate wild-type Ire1, which is tightly regulated on its luminal side. On the other hand, our observations shown in Fig. 6 cumulatively indicate that UPR was fully induced by weak ER stress when the cellular ADP/ATP ratio was increased. In other words, the cellular ADP/ATP ratio can affect the sensitivity of Ire1 to ER-stressing stimuli.

In conclusion, the kinase region of Ire1 per se contributes to its responsiveness to ER stress. As aforementioned, Papa et al. ${ }^{34}$ indicated that a kinase-dead and functionless mutant of Ire 1 functions in the presence of an ATP analogue, suggesting a role of the Ire1 kinase region that is not directly linked to phosphotransfer. It is currently known that ADP interacts with the ATP-binding pocket of Ire1 and acts as an activation ligand of Ire $1^{8-10}$. Our present study thus explains the physiological meaning of this issue. We propose that the cytosolic $\mathrm{ADP} / \mathrm{ATP}$ ratio is monitored by the kinase region of Irel for fine tuning of the UPR.

\section{Methods}

Yeast culture. S. cerevisiae cells were aerobically and exponentially grown at $30^{\circ} \mathrm{C}$ in standard synthetic dextrose (SD) medium containing $2 \%$ glucose, $0.66 \%$ yeast nitrogen base without amino acids (MP Biomedicals) and appropriate auxotrophic requirements. Alternatively, induction of the GAL1 promoter was performed as described previously ${ }^{24}$. To stress cells, tunicamycin $(2 \mathrm{mg} / \mathrm{ml}$ stock in dimethyl sulfoxide), sodium azide ( $2 \%$ stock in water) and DTT (1 M stock in water) were added into the cultures which were then further incubated. The composition of SD medium not containing inositol (SD -ino) was described previously ${ }^{24}$. For the inositoldepletion experiment, cells were exponentially grown in normal SD medium, were washed 6 times with SD (-ino), and were further cultured in SD (-ino).

Yeast strains and plasmids. In the present study, we employed S. cerevisiae ire $1 \Delta$ strain KMY1015 (MAT $\alpha$

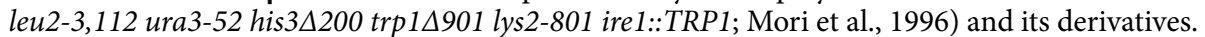

The single-copy IRE1 plasmid pRS313-IRE1 and the hemagglutinin (HA)-tagged Ire1 (Ire1-HA) plasmid pRS315-IRE1-HA were described previously ${ }^{12}$. Point and partial deletion mutations were introduced into pRS313-IRE1 and pRS315-IRE1-HA as described previously using the overlap PCR and in vivo homologous recombination techniques ${ }^{12}$. See the supplementary Methods for the detailed procedure. The $\Delta \mathrm{I}, \Delta \mathrm{III}$ and $\Delta \mathrm{V}$ mutations respectively correspond to amino-acid deletions of a.a. 32-91, a.a. 253-272 and a.a. 463-524. For the UPRE-lacZ reporter assay, cells were transformed with plasmid pCZY ${ }^{26}$. In the experiments shown in Figs. 1, 2 and 5, and supplementary Figs S2, S10, S11 and S12, cells carried pRS315-IRE1-HA or its mutant versions, and thus produced the C-terminal HA-tagged Ire1 or its mutants.

Plasmid pRS313-GAL1pr-CPY*-GFP and a $2 \mu$-based Ire1-HA-expression plasmid pRS426-IRE1-HA are described in Ref. ${ }^{24}$. We introduced IRE1 mutations into pRS426-IRE1-HA as done for pRS313-IRE1 or pRS315IRE1-HA. Empty vectors pRS313 and pRS315 are described in Ref. ${ }^{36}$. 
Screening for mutants that intramolecularly suppress the functionless phenotype of $\Delta I \Delta I I I \Delta V$ Ire1. A randomly mutagenized DNA segment corresponding to the $\mathrm{N}$-terminal half of $\Delta \mathrm{I} \Delta \mathrm{III} \Delta \mathrm{V}$ Ire 1 , which covers its luminal domain, was obtained by low-fidelity PCR amplification from the $\triangle \mathrm{I} \Delta \mathrm{III} \Delta \mathrm{V} I R E 1$ gene using the GeneMorph Random Mutagenesis Kit (Stratagene) and the IRE1-specfic primer set [P1/P2] (supplementary Table S1). The PCR product DNA $(1 \mu \mathrm{g}, 200 \mathrm{ng} / \mu \mathrm{L}$ in TE buffer) and SalI/XbaI-digested pRS315-IRE1HA (100 ng, $100 \mathrm{ng} / \mu \mathrm{L}$ in TE buffer) were mixed and used for transformation of KMY1015 carrying pCZY1. This procedure generated the circular version of pRS315-IRE1-HA carrying the $\Delta \mathrm{I} \Delta \mathrm{III} \Delta \mathrm{V}$ and random point mutation(s) through in vivo homologous recombination in the transformant cells ${ }^{12}$. For the first screening, transformant colonies were transferred to 5-bromo-4-chloro-3-indolyl $\beta$-D-galactopyranoside (X-gal) agar plates $^{37}$, and bluish clones were selected. A second screening was performed via liquid culturing and quantitative cellular $\beta$-galactosidase assay of candidate clones.

Yeast protein analysis. After being harvested through centrifugation at $1,800 \mathrm{Xg}$ for $2 \mathrm{~min}, 20 \mathrm{OD}_{600}$ cells were broken by agitation (top-speed vortexing at $4{ }^{\circ} \mathrm{C}$ for $5 \mathrm{~min}$ ) with glass beads $(425-600 \mu \mathrm{m})$ in $200 \mu \mathrm{l}$ of the lysis buffer (50 mM Tris-Cl (pH7.9), 5 mM EDTA and 1\% Triton X-100 supplemented with protease inhibitors, which is described in Ref. ${ }^{38}$ ). The cell lysates were then clarified by centrifugation at 8,000 Xg for $10 \mathrm{~min}$.

Protein samples were fractionated by the standard Laemmli SDS-PAGE ( $8 \%$ acrylamide) as described in Ref. ${ }^{38}$, and were transferred onto the polyvinylidene difluoride-based Western-bolotting membrane (Hybond-P; GE Healthcare). The semi-dry electrophoretic transfer and subsequent treatment of the blot membranes were performed as indicated by manufacturer's instruction. The primary antibodies used in this study were 12CA5 mouse monoclonal anti-HA antibody $(1 \mu \mathrm{g} / \mathrm{ml})$, mouse monoclonal anti-GFP antibody (1:1,000 dilution, MBL) and 22C5D8 mouse monoclonal anti-PGK1 antibody (1:2,000 dilution, Abcam). The secondary antibodies used in this study were horseradish peroxidase (HRP)-conjugated goat polyclonal anti-mouse IgG antibody (1:2,000 dilution, Jackson). After application of the enhanced chemiluminescence (ECL) reagent (GE healthcare), we quantitatively detected ECL signal on the blot membranes using the luminescence imager LAS4000 (Fuji Film). Precision Plus Dual Color Standards (Bio-Rad) was employed as the molecular-mass marker for SDS-PAGE.

The Phos-tag SDS-PAGE, which was followed by the anti-HA Western blotting, was performed through the same procedure as done in the standard Laemmli SDS-PAGE, with the following exceptions. The lysis buffer did not contain EDTA, but was supplemented with a phosphatase-inhibitor mixture (Phos-stop, Roche). See supplemental Table S2 for the recipe of the Phos-tag acrylamide gel.

See the supplementary Methods for the procedure employed in the experiment shown in supplementary Fig. S4.

RNA analyses. We used the hot-phenol method to extract total RNA from cells ${ }^{38}$. Approximately $\mathrm{OD}_{600}=5.0$ cells were suspended in $1 \mathrm{ml}$ of $50 \mathrm{mM}$ sodium acetate (pH5.3), 10 mMEDTA and 1\% EDTA, and were mixed with hot $\left(65^{\circ} \mathrm{C}\right)$ water-saturated phenol. The mixture was then incubated at $65^{\circ} \mathrm{C}$ for 30 min with occasional top-speed vortexing, and was fractionated by centrifugation $(8,000 \mathrm{Xg}, 10 \mathrm{~min})$. The aqueous fraction was subjected to phenol-chloroform extraction twice, and total RNA was precipitated through the standard ethanolprecipitation procedure.

The RNA samples were treated with the AccuRT genomic DNA removal kit (Applied Biological Materials) and were subjected to the reverse-transcription reaction using the ReverTra Ace kit (Toyobo) and the poly $(\mathrm{dT})_{18}$ oligonucletotide primer as described in manufactures' instructions. The resulting reaction mixture was then employed as a cDNA sample.

In order to monitor HAC1 splicing, $2 \mu \mathrm{l}$ of the cDNA samples were subjected to $25 \mu \mathrm{l}$-scale PCR using the KAPATaq PCR kit (Nihon Genatics) and 10 pmol each of the HAC1-specific primer set (Table S1) in the Thermal cycler PC320 (Astec) that was programmed as follows: $5 \mathrm{~min}$ at $96^{\circ} \mathrm{C}, 25$ cycles at $94{ }^{\circ} \mathrm{C}$ for $30 \mathrm{~s}, 54{ }^{\circ} \mathrm{C}$ for $30 \mathrm{~s}$ and $72{ }^{\circ} \mathrm{C}$ for $60 \mathrm{~s}$, and $7 \mathrm{~min}$ at $72^{\circ} \mathrm{C}$. The PCR products were fractionated by electrophoresis on $2 \%$ agarose gel, the ethidium bromide-stained image of which was used to estimate the HAC1 mRNA-splicing efficiency, which was calculated using the formula: $100 \times[$ (band intensity of the spliced form $) /\{$ (band intensity of the spliced form $)+($ band intensity of the unspliced form) $\}]$.

For the RT-qPCR analysis, the cDNA samples were subjected to real-time PCR as described in Ref. ${ }^{38}$. The KAR2-specific primer set, the HAC1-specific primer set and the reference TAF10-specific primer set are listed in Table $\mathrm{S} 1$.

In vitro protein aggregation assay. The Escherichia coli expression plasmid for MBP-tagged cLD (MBPcLD), which was previously called MBP-CSSR, is described in our previous publication ${ }^{20}$. MBP-cLD and its mutant versions were expressed in the E. coli strain BL21 codon plus (DE3)-RIL (Strategene) and purified as described previously ${ }^{20}$.

In vitro protein aggregation assays were also performed basically as described previously ${ }^{20}$. In brief, luciferase ( $25 \mu \mathrm{M}$ final concentration) and citrate synthase (50 $\mu \mathrm{M}$ final concentration) were incubated in the guanidine $\mathrm{HCl}$-denaturing solution (guanidine $\mathrm{HCl}$ ( $6 \mathrm{M}$ for luciferase or $4 \mathrm{M}$ for citrate synthase), $20 \mathrm{mM}$ Hepes, $50 \mathrm{mM}$ $\mathrm{KCl}$, and $2 \mathrm{mM} \mathrm{MgCl}_{2}$ ) for $30 \mathrm{~min}$ at room temperature. The denaturing mixture was then diluted with the assay buffer (20 mM Hepes, pH 7.2, $50 \mathrm{mM} \mathrm{KCl}$, and $2 \mathrm{mM} \mathrm{MgCl}_{2} ; 40$-fold dilution for luciferase and 100-fold dilution for citrate synthase) containing $1 \mu \mathrm{M}$ MBP-cLD or its mutants. The resulting mixtures were then incubated at $25^{\circ} \mathrm{C}$ for $5 \mathrm{~min}$, and protein aggregation was monitored by measuring turbidity (absorbance at $320 \mathrm{~nm}$ on a Shimadzu UV-1800 spectrophotometer). 
Other techniques. Culture optical density $\left(\mathrm{OD}_{600}\right)$ was measured using the SmartSpec 3000 spectrophotometer (BioRad).

In order to estimate the cellular ADP/ATP ratio, cellular metabolism was quenched by mixing $100 \mu \mathrm{l}$ of culture with $200 \mu \mathrm{l}$ of $-40^{\circ} \mathrm{C}$ methanol. Cells were lysed by adding $200 \mu \mathrm{l}$ of acetonitrile into the mixture, which was then agitated with $30 \mathrm{~s}$ top-speed vortexing. The resulting cell lysates were dried in a speed vac evaporator and were subjected to the bioluminescent analysis using the EnzyLight ADP/ATP Ratio Assay Kit (BioAssay Systems).

See the supplementary Methods for the procedure of UPRE-lacZ reporter assay. The procedure for the cell survival assay is also described in the supplementary Methods.

Statistics. For the RNA analyses, the cell survival assay, the growth curve measurement and the UPR-lacZ reporter assays, triplicate biological replicates (three independent transformants with pRS313-IRE1, pRS315IRE1-HA, their variants or the empty vectors) were assayed per one condition, and results are presented as the averages and standard deviations.

In order to obtain $p$ values, we performed two-tail unpaired t-Test (for Figs. 1, 2, 3, 4a, 6e, 7b,c, and supplementary Figs S2, S5 and S7) and paired t-Test (for Figs. 4b-e, 6a,b,d and 7a, and supplementary Figs S6, S8 and S9) using Microsoft Excel.

Received: 14 April 2020; Accepted: 5 February 2021

Published online: 24 February 2021

\section{References}

1. Ron, D. \& Walter, P. Signal integration in the endoplasmic reticulum unfolded protein response. Nat. Rev. Mol. Cell Biol. 8, 519-529 (2007).

2. Mori, K. Signalling pathways in the unfolded protein response: development from yeast to mammals. J. Biochem. 146, 743-750 (2009).

3. Cox, J. S. \& Walter, P. A novel mechanism for regulating activity of a transcription factor that controls the unfolded protein response. Cell 87, 391-404 (1996).

4. Travers, K. J. et al. Functional and genomic analyses reveal an essential coordination between the unfolded protein response and ER-associated degradation. Cell 101, 249-258 (2000).

5. Kimata, Y., Ishiwata-Kimata, Y., Yamada, S. \& Kohno, K. Yeast unfolded protein response pathway regulates expression of genes for anti-oxidative stress and for cell surface proteins. Genes Cells 11, 59-69 (2006).

6. Kawahara, T., Yanagi, H., Yura, T. \& Mori, K. Endoplasmic reticulum stress-induced mRNA splicing permits synthesis of transcription factor Haclp/Ern4p that activates the unfolded protein response. Mol. Biol. Cell 8, 1845-1862 (1997).

7. Shamu, C. E. \& Walter, P. Oligomerization and phosphorylation of the Irelp kinase during intracellular signaling from the endoplasmic reticulum to the nucleus. EMBO J. 15, 3028-3039 (1996).

8. Lee, K. P. et al. Structure of the dual enzyme Ire1 reveals the basis for catalysis and regulation in nonconventional RNA splicing. Cell 132, 89-100 (2008).

9. Korennykh, A. V. et al. The unfolded protein response signals through high-order assembly of Ire1. Nature 457, 687-693 (2009).

10. Korennykh, A. V. et al. Cofactor-mediated conformational control in the bifunctional kinase/RNase Ire1. BMC Biol. 9, 48 (2011).

11. Kimata, Y. \& Kohno, K. Endoplasmic reticulum stress-sensing mechanisms in yeast and mammalian cells. Curr. Opin. Cell Biol. 23, 135-142 (2011).

12. Kimata, Y., Oikawa, D., Shimizu, Y., Ishiwata-Kimata, Y. \& Kohno, K. A role for BiP as an adjustor for the endoplasmic reticulum stress-sensing protein Ire1. J. Cell Biol. 167, 445-456 (2004).

13. Oikawa, D., Kimata, Y., Takeuchi, M. \& Kohno, K. An essential dimer-forming subregion of the endoplasmic reticulum stress sensor Ire1. Biochem. J. 391, 135-142 (2005).

14. Credle, J. J., Finer-Moore, J. S., Papa, F. R., Stroud, R. M. \& Walter, P. On the mechanism of sensing unfolded protein in the endoplasmic reticulum. Proc. Natl. Acad. Sci. US A 102, 18773-18784 (2005).

15. Pincus, D. et al. BiP binding to the ER-stress sensor Irel tunes the homeostatic behavior of the unfolded protein response. PLoS Biol. 8, e1000415 (2010).

16. Mathuranyanon, R. et al. Tight regulation of the unfolded protein sensor Ire1 by its intramolecularly antagonizing subdomain. J. Cell Sci. 128, 1762-1772 (2015).

17. Okamura, K., Kimata, Y., Higashio, H., Tsuru, A. \& Kohno, K. Dissociation of Kar2p/BiP from an ER sensory molecule, Ire1p, triggers the unfolded protein response in yeast. Biochem. Biophys. Res. Commun. 279, 445-450 (2000).

18. Bertolotti, A., Zhang, Y., Hendershot, L. M., Harding, H. P. \& Ron, D. Dynamic interaction of BiP and ER stress transducers in the unfolded-protein response. Nat. Cell Biol. 2, 326-332 (2000).

19. Kimata, Y. et al. Genetic evidence for a role of BiP/Kar2 that regulates Ire1 in response to accumulation of unfolded proteins. Mol. Biol. Cell 14, 2559-2569 (2003).

20. Kimata, Y. et al. Two regulatory steps of ER-stress sensor Irel involving its cluster formation and interaction with unfolded proteins. J. Cell Biol. 179, 75-86 (2007).

21. Gardner, B. M. \& Walter, P. Unfolded proteins are Ire1-activating ligands that directly induce the unfolded protein response. Science 333, 1891-1894 (2011).

22. Liu, C. Y., Schroder, M. \& Kaufman, R. J. Ligand-independent dimerization activates the stress response kinases IRE1 and PERK in the lumen of the endoplasmic reticulum. J. Biol. Chem. 275, 24881-24885 (2000).

23. Oikawa, D., Kimata, Y. \& Kohno, K. Self-association and BiP dissociation are not sufficient for activation of the ER stress sensor Ire1. J. Cell Sci. 120, 1681-1688 (2007).

24. Promlek, T. et al. Membrane aberrancy and unfolded proteins activate the endoplasmic reticulum stress sensor Ire1 in different ways. Mol. Biol. Cell 22, 3520-3532 (2011).

25. Mori, K., Kawahara, T., Yoshida, H., Yanagi, H. \& Yura, T. Signalling from endoplasmic reticulum to nucleus: transcription factor with a basic-leucine zipper motif is required for the unfolded protein-response pathway. Genes Cells 1, 803-817 (1996).

26. Mori, K. et al. A 22 bp cis-acting element is necessary and sufficient for the induction of the yeast KAR2 (BiP) gene by unfolded proteins. EMBO J. 11, 2583-2593 (1992).

27. Halbleib, K. et al. Activation of the unfolded protein response by lipid bilayer stress. Mol. Cell 67, 673-684 (2017).

28. Tran, D. M., Takagi, H. \& Kimata, Y. Categorization of endoplasmic reticulum stress as accumulation of unfolded proteins or membrane lipid aberrancy using yeast Ire1 mutants. Biosci. Biotechnol. Biochem. 83, 326-329 (2019). 
29. Rubio, C. et al. Homeostatic adaptation to endoplasmic reticulum stress depends on Ire1 kinase activity. J. Cell Biol. 193, 171-184 (2011).

30. Ishiwata-Kimata, Y., Promlek, T., Kohno, K. \& Kimata, Y. BiP-bound and nonclustered mode of Ire1 evokes a weak but sustained unfolded protein response. Genes Cells 18, 288-301 (2013).

31. Bowler, M. W., Montgomery, M. G., Leslie, A. G. \& Walker, J. E. How azide inhibits ATP hydrolysis by the F-ATPases. Proc. Natl. Acad. Sci. USA 103, 8646-8649 (2006).

32. Cox, J. S., Shamu, C. E. \& Walter, P. Transcriptional induction of genes encoding endoplasmic reticulum resident proteins requires a transmembrane protein kinase. Cell 73, 1197-1206 (1993).

33. Mai, C. T. et al. Dispersion of endoplasmic reticulum-associated compartments by 4-phenyl butyric acid in yeast cells. Cell Struct. Funct. 44, 173-182 (2019).

34. Papa, F. R., Zhang, C., Shokat, K. \& Walter, P. Bypassing a kinase activity with an ATP-competitive drug. Science 302, 1533-1537 (2003).

35. Chawla, A., Chakrabarti, S., Ghosh, G. \& Niwa, M. Attenuation of yeast UPR is essential for survival and is mediated by IRE1 kinase. J. Cell Biol. 193, 41-50 (2011).

36. Sikorski, R. S. \& Hieter, P. A system of shuttle vectors and yeast host strains designed for efficient manipulation of DNA in Saccharomyces cerevisiae. Genetics 122, 19-27 (1989).

37. Kaiser C., Michaelis S. \& Mitchell A. Methods in Yeast Genetics: A Cold Spring Harbor Laboratory Course Manual (Cold Spring Harbor Laboratory, 1994).

38. Mai, C. T. et al. 4-Phenylbutyrate suppresses the unfolded protein response without restoring protein folding in Saccharomyces cerevisiae. FEMS Yeast Res. 18, foy016 (2018).

\section{Acknowledgements}

We deeply thank to Prof. Hiroshi Takagi (Nara Inst. Sci. Tech.) for a wide variety of valuable supports, which have been indispensable for this study. This study is supported by research grants from Ohsumi Frontier Science Foundation and Noda Institute for Scientific Research to Y.K..

\section{Author contributions}

Y.K. and K.K. developed the theoretical framework. Q.G.L. and Y.I-K. constructed DNA plasmids and performed the experiments. T.H.P. performed RNA analyses. S.F. isolated the Y225H mutant. Y.K. designed the experiments and completed the manuscript. All authors reviewed the manuscript.

\section{Competing interests}

The authors declare no competing interests.

\section{Additional information \\ Supplementary Information The online version contains supplementary material available at https://doi. org/10.1038/s41598-021-83890-x.}

Correspondence and requests for materials should be addressed to Y.K.

Reprints and permissions information is available at www.nature.com/reprints.

Publisher's note Springer Nature remains neutral with regard to jurisdictional claims in published maps and institutional affiliations.

(c) (1) Open Access This article is licensed under a Creative Commons Attribution 4.0 International License, which permits use, sharing, adaptation, distribution and reproduction in any medium or format, as long as you give appropriate credit to the original author(s) and the source, provide a link to the Creative Commons licence, and indicate if changes were made. The images or other third party material in this article are included in the article's Creative Commons licence, unless indicated otherwise in a credit line to the material. If material is not included in the article's Creative Commons licence and your intended use is not permitted by statutory regulation or exceeds the permitted use, you will need to obtain permission directly from the copyright holder. To view a copy of this licence, visit http://creativecommons.org/licenses/by/4.0/.

(C) The Author(s) 2021 